\title{
Some of my friends
}

Some of my friends are becoming concerned.

About lumps where there were none before. Some thing which does not look right. Their comforts undermined by pains sharp or dull.

The need to draw breath into deeper places.

Some are feeling vulnerable.

Their eyes are clouding, words appearing to dissolve, sounds soft and muffled. Some of my friends need procedures and further testing. They will have to travel to someplace far and unfamiliar and wait.

They will try to recall when sleep came easy.

Now they might have to be kept overnight, have blood let by girls named Betty. Lie beneath beams which will turn their skin to rice paper. All of their functions will be distilled to graphs and digits.

Some of my friends seem to be wearing out. Their pink becoming grey. Their tightness loosened. Some will be told today.

\section{Daniel Thomas Moran}

Correspondence to Daniel Thomas Moran, School of Dental Medicine/Department of General Dentistry, Boston University, 100 E. Newton St., Boston, MA 02118, USA; dan@danielthomasmoran.net

Competing interests None.

Contributors DTM is the sole contributor and author and has all rights to this poem.

Provenance and peer review Not commissioned; internally peer reviewed.

Published Online First 23 August 2011

Med Humanit 2012;38:e7. doi:10.1136/medhum-2011-010081 